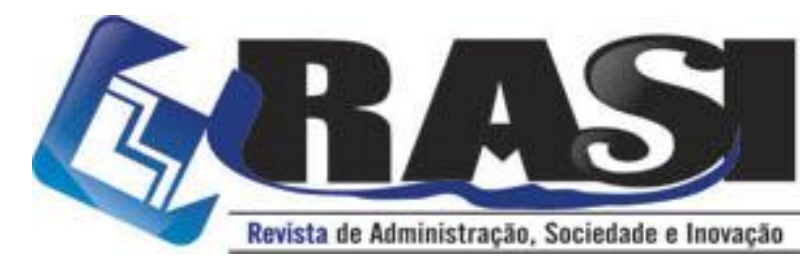

http://www.rasi.uff.br

RASI, Volta Redonda/RJ, v. 1, n. 1, pp. 37-52, Jul./Dez. 2015.

\title{
Gerenciamento de Procedimentos Operacionais através de Sistema Informativo: Estudo de Caso da KB Cervejarias
}

\author{
Luan Eloy de Lima - Centro Universitário do Norte (UNINORTE) - \\ luan_elloy@hotmail.com \\ Flávia Roberta Ferreira de Souza - Universidade Paulista (UNIP)
}

\begin{abstract}
Resumo: Este artigo se propõe analisar o Gerenciamento de Procedimentos Operacionais dentro da KB Cervejarias, empresa atuante no mercado cervejeiro na cidade de Manaus, Amazonas. O estudo de caso envolveu coleta de dados em todo o ambiente interno da organização em estudo, a aplicação dos formulários, que geraram dados estatísticos, permitindo a análise qualitativa e quantitativa dos aspectos que corrupiam o sistema de controle de documentos padronizados. Com foco nos objetivos propostos pela pesquisa, as categorias investigadas estão relacionadas ao sistema informativo, padronização, confiabilidade dos funcionários nas ferramentas propostas pela empresa e sistematização de atividades. Sendo assim, foi possível demonstrar o grau de saturação que a KB Cervejarias apresentava quando relacionado aos aspectos de controle e gerenciamento de procedimentos operacionais enquanto a revisão, disposição, criação e treinamento de seus colaboradores nos padrões documentados, interferindo negativamente no andamento do negócio e sua posição de mercado. Com isso, a organização regia suas atividades sem estabilidade por conta do alto índice de desrespeito aos aspectos íntegros do produto, uma lacuna deixada pela ausência de controle dos procedimentos operacionais.
\end{abstract}

Palavras-Chave: Procedimentos; Tecnologia; KB Cervejarias; Padronização.

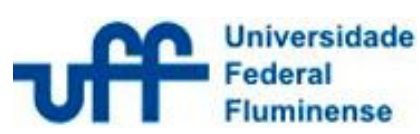

R. Desembargador Ellis Hermydio Figueira, 783, Bloco A, sl. 218, Aterrado.

27213-415 - Volta Redonda, RJ - Brasil

www.uff.br

Copyright (C) 2015 RASI. Todos os direitos, até mesmo de tradução, são reservados. É permitido citar parte de artigos sem autorização prévia, desde que seja identificada a fonte. 


\section{Gerenciamento de Procedimentos Operacionais através de Sistema Informativo: Estudo de Caso da KB Cervejarias}

\section{Introdução}

Os Procedimentos Operacionais (PO's) são documentos de interface com as atividades rotineiras, que tendem a padronizá-las de modo a gerar um ponto de referência para qual as tarefas devem ser efetuadas através dos colaborares, tais documentos, são essenciais para o processo de Controle de Qualidade Total, gerando maior assertividade na especificação do produto ou serviço. Os PO's devem ser claros e concisos de modo a garantir que através da capacitação dos agentes internos haja a execução correta das atividades. A tecnologia recorrente atual facilita a disponibilização destes documentos de capacitação, gerando um método comunicativo eficiente dentro das organizações.

A KB Cervejarias é uma das maiores empresas estrangeiras atuante no Brasil de acordo com as pesquisas de mercado apresentadas pela revista eletrônica EXAME.COM, a mesma atua na cidade de Manaus há cinco anos com dispersão de seus produtos por toda a região norte do país.

$\mathrm{O}$ artigo visa apresentar melhoria no sistema de controle e gerenciamento dos documentos de padronização de atividades a fim de gerar maior confiabilidade e eficiência no sistema de treinamento dos funcionários, para que o desempenho da $\mathrm{KB}$ Cervejarias tenha melhor resultado no segmento em que atua.

Este estudo tem como objetivo analisar o usufruto de sistema informativo que gerencie e controle os procedimentos operacionais internos, com tudo, torna-se fundamental a delimitação e distribuição dos PO's por todas as áreas da empresa, controle de revisões e atualizações dos documentos de padronização e gerenciamento continuo com o uso de software ${ }^{1}$.

A organização em análise apresenta dificuldades enquanto a estabilidade no mercado por conta do grande número de retrabalho gerado pela ausência de controle dos padrões operacionais de suas atividades, pois os mesmos encontram-se defasados, desatualizados e por muitas vezes com ausência de disposição para consulta e capacitação por parte dos colaboradores.

\section{Sistema de Gestão da Qualidade (SGQ)}

O Sistema de Gestão da Qualidade tem por finalidade a criação de uma metodologia empresarial focada no contínuo aprimoramento do desempenho dos processos, usufruindo de ferramentas como: procedimentos operacionais, planilhas de controle de processos, fluxogramas, histogramas e etc. Conforme apresentado pelo estudo de Thielmann e Schmidt (2014) o Sistema de Gestão da Qualidade (SGQ) contribui para a organização no sentido de garantir de maneira padronizada e

\footnotetext{
${ }^{1}$ Software: Subsistema de um sistema computacional. São os programas de computadores. (REZENDE, 2005).
} 
sistemática que seus processos atendam ás necessidades e expectativas dos clientes através da melhoria contínua.

Para a implementação do SGQ é necessário o envolvimento e comprometimento de toda a corporação.

De acordo com a Pearson Academia (2011):

Os principais instrumentos preconizados pela gestão da qualidade relacionam-se a mudanças na forma de pensar os produtos, serviços e seus respectivos processos. Todos, dentro da empresa, precisam estar envolvidos com a qualidade, e para isso, envidam-se esforços em treinamentos e programas de qualidade.

O foco de toda organização deve estar voltado ao cliente, àquele que fornece meios para que seus negócios continuem ativos, com isso, faz-se necessário total atendimento ao que o cliente estipula como qualidade. Sendo assim, o cliente envia a mensagem (sua necessidade/desejo), a organização trabalha em cima desta e redistribui para os demais departamentos que possam, de alguma maneira, influenciar no resultado final. Tais informações fazem parte do controle total da qualidade, onde o processo recorre através de procedimentos operacionais para chegar até as mãos dos colaboradores.

Conforme apontado por Campos (2014):

O objetivo do controle integrado da qualidade é a garantia da satisfação do cliente [...] as informações fluem do mercado (cliente) para as especificações do produto, dessas para o projeto do produto e para o padrão técnico de processo. Do padrão técnico de processos as informações vão para o operador por meio dos procedimentos operacionais.

Com o envolvimento de todos os colaboradores a organização deve incorporar uma cultura nova e vivenciar treinamentos e capacitação por novos meios que tendem a gerar vantagem competitiva para a empresa, adquirindo, neste processo, diversas ferramentas que facilitem a implementação deste sistema de gestão.

\section{Procedimentos Operacionais (PO's)}

A KB Cervejarias vem passando por diversas mudanças e adequações no decorrer dos anos devido às tendências e necessidades que o mercado implica dentro da organização. A cada dia que se passa, o cliente exige por maior grau de qualidade de todos os produtos e serviços que lhe são ofertados, não seria diferente quando aplicamos o foco na empresa analisada. A KB Cervejarias constantemente procura adequar seu produto para um maior grau de aceitabilidade por parte da sua clientela e usa dos procedimentos operacionais padrões para criar um canal de comunicação direta com os colaboradores. 
Os procedimentos operacionais (PO's) são documentos internos ou externos que apresentam minuciosamente a realização de atividades de modo a criar um padrão a ser seguido pelos realizadores. É importante que os procedimentos operacionais estejam em constante atualização seguindo o modelo de melhoria contínua, onde todos os processos estão em adequação com o direcionamento de melhorar o desempenho da empresa.

Os PO's são apontados por Verri (2009) de forma que um padrão é um procedimento, um objeto de referência, ou um processo especifico, o qual estabelece como um trabalho ou serviço deve ser executado.

A ação de padronização das atividades através dos documentos operacionais tem grande importância para o diferencial competitivo que a organização apresenta. Manter estipulado quem faz o quê, quando e onde, é um método de padronização, entretanto, tal aspecto vai muito além disto. As organizações dos dias de hoje necessitam constantemente atender a um padrão. Um produto, por exemplo, não pode chegar às mãos de um cliente com determinado tamanho, enquanto outro é produzido em medidas diferentes. Padronizar é uma questão de atender ao esperado e cumprir com o oferecido, sendo assim, uma das mais importantes garantias de definição de rotinas para atender ao consumidor.

Campos (2014) dissemina que nas empresas modernas do mundo a padronização é considerada a mais fundamental das ferramentas gerenciais. Na qualidade total a padronização é a base para a rotina (gerenciamento da rotina do trabalho diário).

O principal foco da padronização é conseguir que cada colaborador, independente de estar familiarizado com determinada atividade ou tarefa ou não, consiga executá-la dentro dos padrões aceitáveis como 'com qualidade' repetidas vezes. É o fator de tentar fazer com que todos entendam o processo de maneira clara e objetiva, agindo com eficiência.

Os processos internos agem como um jogo de válvulas que em conjunto circulam corretamente quando os objetivos são estabelecidos e cumpridos. Quando voltado para a comunicação operacional, precisamos criar um método de garantir sua efetividade e o conhecimento comum desta por parte dos colaboradores.

A operação de procedimentos internos colabora com estes objetivos, como explora Ribeiro Neto, Tavares e Hoffmann (2013) para permitir consistência das ações, prover treinamento apropriado, assegurar repetibilidade e prover evidência objetiva de que resultados desejados foram atingidos.

\section{Usufruto de Tecnologia na KB Cervejarias}

A KB Cervejarias desenvolveu o uso de procedimentos operacionais para adequar suas atividades de forma padronizada, entretanto, não houve o controle de procedimentos, tornando tal ferramenta defasada, disponibilizando documentos 
desatualizados e dispersos, sem gerenciamento de disposição, revisão, atualização, criação, responsabilidades no processo de gerenciamento, apontando falhas em uma rotina que deveria gerar vantagem competitiva para a empresa em frente à era onde $\mathrm{o}$ conhecimento é o verdadeiro capital diferencial nos negócios.

O avanço tecnológico proporcionou grande gestão de controle para as empresas. Tudo se torna digital, e o uso deste recurso pode alavancar os negócios extraindo diversos diferenciais. Um dos principais atributos do desenvolvimento da tecnologia é a TI (Tecnologia da Informação), onde o principal objetivo é fornecer dados que deem sustentabilidade à tomada de decisão em um universo onde cobra-se cada vez mais agilidade para geração de vantagem competitiva.

O’Brien e Marakas (2013) definem conforme disposto:

A tecnologia da informação é capaz de auxiliar todos os tipos de negócios a aprimorar a produtividade e a eficácia de seus processos administrativos, a tomada de decisão gerencial e a colaboração de grupos de trabalho, reforçando suas posições competitivas em um mercado de mudanças rápidas, independentemente de a tecnologia da informação ser usada para apoiar grupo de desenvolvimento de produtos ou processos de atendimento ao cliente, transações de comércio eletrônico (e-commerce) ou qualquer outra atividade comercial.

Informação é o diferencial competitivo das pessoas e das organizações do século. É o que move o mercado. Milhares de negócios estão fechando suas portas por não saber utilizar das informações que tem ou por não desenvolver metodologia para captá-las. Saber como, onde e quando aplicar determinado conhecimento pode trazer grandes retornos para as empresas. Por isso, requer que as informações sejam gerenciadas e analisadas formalmente, sem a oportunidade de perdê-las ou deixá-las passar por despercebido.

Destaca-se através do relato de Rezende (2013):

As informações sistematizadas podem representar diferenciais nas organizações e nas pessoas que pretendem destacar-se no mercado e na sociedade. A informação deve ser considerada como diferencial quando proporciona alternativas de retornos profícuos para a organização, sedimentando as atuais atividades ou criando novas oportunidades.

A organização em estudo pode utilizar dos meios e ferramentas que a tecnologia oferece para otimizar o controle e gerenciamento dos procedimentos operacionais, revitalizando o processo de padronização para melhorar o desempenho dos seus negócios diminuindo as atividades de retrabalho. 


\title{
5. Gerenciamento Eletrônico de Documentos (GED)
}

O avanço tecnológico auxilia continuamente o desempenho das organizações, tal suporte não seria diferente quando trata-se do gerenciamento eletrônico de procedimentos operacionais. É de suma importância para garantir vantagem competitiva para as organizações que os procedimentos operacionais estejam dispostos para todos que necessitem realizar consulta ou capacitação, assim como faz-se necessária a constante atualização e disponibilização. Através do sistema de gerenciamento eletrônico de documentos possibilita-se o fornecimento de controle total sobre os procedimentos operacionais, criando uma central de usuários que aponte um fluxograma de autorização para revisões e criação de novos procedimentos, esclarecendo o papel de importância que cada um dos colaboradores contidos no fluxograma possa ter.

Sistemas como o GED, geram: o transmissor que como o próprio nome já diz, é quem envia a mensagem e a transforma entendível para o canal, no caso, um software que seria utilizado para a distribuição de tais documentos, que se encarrega de fugir dos ruídos para entregar a mensagem para o receptor, quando aplicado ao caso dos procedimentos, é o objetivo final do canal, que deve aderir ao conteúdo e realizar as atividades conforme dispostas na documentação padrão, garantindo assim, os objetivos anteriormente apresentados.

Conforme Chiavenato (2014):

\begin{abstract}
Em todo sistema de informação, a fonte serve para fornecer mensagens. $\mathrm{O}$ transmissor opera nas mensagens emitidas pela fonte, transformando-as em forma adequada ao canal. Este leva a mensagem sob a nova forma para um local distante. $\mathrm{O}$ ruído perturba a mensagem ao canal. O receptor decifra a mensagem gravada no canal e a transforma em uma forma adequada ao destino.
\end{abstract}

O GED, ou, Gerenciamento Eletrônico de Documentos, é a fusão do uso da tecnologia com a vantagem competitiva gerada pela informação, onde todos os dados selecionados ficam disponíveis online com o mesmo valor e confiabilidade que os documentos originais.

Carreira (2009) dispõe de tal conceito:

O GED é um sistema de gerenciamento eletrônico de documentos que utiliza a tecnologia da imagem para armazenar, localizar e recuperar documentos. As imagens geradas pelo GED substituem os documentos impressos e têm o mesmo valor do documento original.

O Gerenciamento on-line de documentos viabiliza a constante atualização dos padrões operacionais, pois mesmo que a padronização seja o foco para a acuracidade de produtos ou serviços, vale lembrar que deve estar em adequação contínua, seja para 
melhorar a perspectiva de qualidade, processo ou produtividade, com isso, há a necessidade de revisão dos procedimentos operacionais conforme eles se tornam defasados em relação a atividade, ou quando a corporação enxerga um método melhor para realizar tal tarefa.

Verri (2009) embasa tal comentário falando que o padrão deve ser continuamente melhorado, em termos de busca da Qualidade e da Produtividade.

Os processos estão em constante movimento e os procedimentos devem apresentar exatamente como tal processo anda, por isso, paralelamente à mudanças no processo, faz-se necessária a revisão dos padrões operacionais quando objetivam a melhoria dos resultados.

É relatado pela obra de Campos (2014) que o método padronizado não é fixo: ele pode e deve ser melhorado para a obtenção de melhores resultados. Se os resultados forem melhores, os outros adotarão o método revisto.

Além das facilidades que o GED fornece no âmbito de alteração de procedimentos, pode ser apontada a facilidade enquanto ao treinamento dos colaboradores. A ausência de capacitação pode ser revertida com o uso de procedimentos operacionais padronizados conforme as necessidades de suas atividades ou tarefas. Cabe à organização disponibilizar tal treinamento para usufruir de todo o impulso estratégico possível.

Analisa-se através da obra de Campos (2014) que para que o colaborador possa "trabalhar de acordo com os padrões", é obviamente necessário que haja treinamento operacional competente baseado nos procedimentos operacionais e nas necessidades do posto de trabalho.

\section{Materiais e Métodos}

A metodologia dada ao projeto de pesquisa é descritiva a partir da exposição de determinado objeto de analise para a criação de identificação de problemáticas e variáveis de solução para gerar descrição de problemática e servir como base para tomada de decisão.

Quando trata-se da classificação dos meios de pesquisa, Vergara (2013) enquadra a mesma como um estudo de caso, pois é o circunscrito a uma ou poucas unidades, entendidas essas como [...] produto, empresa, órgão público, comunidade ou mesmo país. Tem caráter de profundidade e detalhamento [...] Utiliza métodos diferenciados de coletas de dados.

O estudo de caso é uma análise embasada em determinado ponto onde apresenta-se os aspectos gerais que podem gerar determinada problemática foco. É através do estudo de caso que possibilita-se entender a organização. Fica estabelecido 
que é necessária autenticidade das informações apresentadas para que tal estudo apresente resultados eficientes, facilitando a implementação de ações que venham solucionar a problemática analisada com a participação do analisador e do analisado.

Conforme explorado por Reis (2008):

O estudo de caso é uma técnica de pesquisa com base empírica. Consiste em selecionar um objeto de pesquisa, que pode ser um fato ou um fenômeno estudado nos seus vários aspectos. Nesse tipo de pesquisa o pesquisador e o participante representante da situação-problema cooperam mutuamente com o estudo.

As ferramentas utilizadas para prover análise e material de pesquisa para a elaboração de tal artigo, foram: análise documental, entrevista, aplicação de questionário e observação direta, as quais proporcionaram dados qualitativos e quantitativos que relacionam o problema raiz com os fatos apresentados.

\subsection{Universo e Amostra}

A KB Cervejarias dispõe de $11.000 \mathrm{~m}^{2}$ construídos na Rua: Comendador Alexandre Amorim, Número 26, Aparecida. A empresa é atuante no mercado de fabricação e engarrafamento de cervejas e chopps com linhas de $600 \mathrm{mls}$ e 50 litros. A organização atua com o uso de 62 funcionários divididos em três turnos, estes, subdividem-se em áreas administrativas e produtivas.

Para iniciação de pesquisa, foi elaborado um questionário com dez perguntas abertas direcionadas ao Gerente de Planta em entrevista no dia 18 de Fevereiro de 2015, com roteiro anteriormente definido, onde podemos questionar sobre as principais problemáticas no sistema de gerenciamento de procedimentos. Durante a entrevista, houve análise documental dos procedimentos apresentados pela área de TPM (Total Productivity Management) para acompanhamento do roteiro. Inicialmente o Gerente contou o histórico da planta e o processo de transição que a mesma está passando devida a troca de Diretor. Foi analisado junto ao entrevistado os documentos que evidenciaram principalmente a não conformidade com o indicador de retrabalho por conta da falta de padrões ou da disposição desatualizada dos mesmos.

No dia 23 e 24 de Março de 2015, foi realizada observação direta in-loco com acompanhamento do Gerente de Instalações Industriais para que o mesmo pudesse nos demonstrar a localização dos procedimentos operacionais dispostos para as áreas produtivas de fabricação, envasamento e embarrilamento.

Utilizamos em 25 de Março, durante os três turnos de trabalho, da aplicação de questionário com perguntas fechadas, com foco nas principais áreas de melhorias para o processo de controle de procedimentos padronizados, de modo que pudéssemos aferir maior grau quantitativo de analise para apoiar os resultados da entrevista posterior. 
Nesta etapa da análise, foi utilizado $80,64 \%$ do quadro funcional ativo na empresa em estudo, resultando em 50 questionários respondidos.

Do universo de 62 funcionários, foram entrevistados posteriormente 50\%, equivalente a 31 colaboradores no dia 26 de Março de 2015, atuantes em cargos gerenciais e na área de produção de produtos engarrafados. As perguntas foram direcionadas para as maiores falhas enquanto aos procedimentos operacionais atuantes na fábrica naquele presente momento, onde tentamos extrair as diversas causas problemáticas que nos levasse à uma causa raiz. Os dados extraídos foram compilados através de uma análise de falhas com resultados qualitativos por meio da ferramenta de Diagrama de Ishikawa, usufruindo dos fatores de: método, máquina, medida, meio ambiente, material e mão-de-obra.

\section{Resultados}

Os questionários que contemplaram 50 funcionários ativos na KB Cervejarias, $80,64 \%$ do quadro total, ressaltou três principais problemáticas conforme apresentado abaixo:

Gráfico 1. Principais problemáticas encontradas no processo de controle de procedimentos operacionais

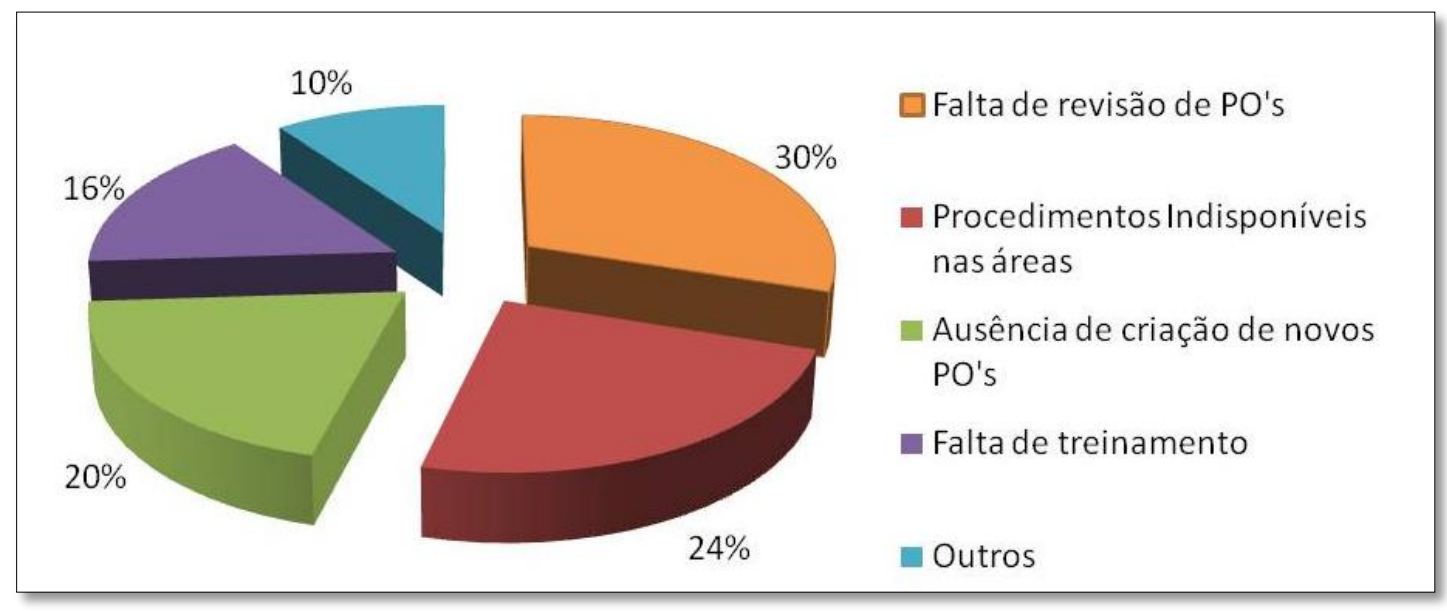

Fonte: Própria, 2015.

Dentro da amostra analisada evidencia-se que 30\% -15 colaboradores- acreditam que a principal problemática é relacionada à falta de revisão dos procedimentos operacionais, pois os mesmos encontram diversas instruções ultrapassadas e defasadas que acarretam na qualidade do produto, impacto no meio-ambiente, segurança do colaborador e aumento no custo de produção. Enquanto aos procedimentos indisponíveis nas áreas, 24\% dos questionários -12 funcionários- apresentaram como uma das maiores causas, relacionando a grande probabilidade de não ter os procedimentos in-loco quando necessário para consulta na execução das tarefas. 
O grupo de 10 colaboradores, representando $20 \%$ da amostra apontou que a ausência de criação de novos PO's é uma grande problemática devido a isenção de padronização de algumas atividades importantes para o melhor desempenho da organização. $\mathrm{Na}$ área de comentários, diversos colaboradores, principalmente operadores da produção, ressaltaram o fato de não estarem envolvidos na criação de procedimentos, quando estes, são aqueles que conhecem com maior detalhamento o desempenho das máquinas.

A causa 'Falta de treinamento' foi priorizada por $16 \%$ dos pesquisados -8 indivíduos- que criticaram a desatualização enquanto a capacitação, pois, não havia um processo de comunicação quando os procedimentos eram revisados. Os demais colaboradores que fizeram parte do quadro da amostra, 5 na totalidade, representante de $10 \%$ direcionaram outras causas como maior problemática no controle e gerenciamento de procedimentos internos.

Através da entrevista com o grupo de 50\% de colaboradores -31 funcionários-, realizada no dia 26 de Março de 2015, ficou claro que o processo de gerenciamento de procedimentos operacionais apresenta diversas falhas. A insatisfação com o processo de revisão, atualização e disponibilização de PO's gerou uma cultura retraída dos colaboradores enquanto aos documentos de padronização, os funcionários perderam a confiança na ferramenta de capacitação e acabam desempenhando suas atividades conforme acham melhor, entretanto, a realização dessas tarefas é feita de forma desordenada pois não há consenso mutuo. Na troca de turno há maior grau de retrabalho devido a falta de comunicação entre os realizadores das tarefas.

Com base nos diversos dados qualitativos obtidos através das entrevistas e com as problemáticas encontradas na observação direta e análise documental, consideramos fundamental utilizar o diagrama de Ishikawa para correlacionar todas os problemas que acarretam na causa raiz. Cada problemática foi relacionada com uma das áreas dos 6 M's trabalhados na -comumente chamada- espinha de peixe ou diagrama de causa e efeito.

De acordo com a passagem de Seleme e Stadler (2012) o diagrama de causa e efeito:

[...] permite estabelecer, após uma análise criteriosa, quais são as causas (problemas que dão início à ocorrência do problema maior) que fazem com que o efeito ocorra. É um diagrama que pretende mostrar a relação entre uma característica da qualidade e seus diversos fatores determinantes.

É apresentado por Lobo e Silva (2014) o conceito de diagrama de causa e efeito como:

Técnica para análise das causas profundas, na transição entre a descrição do problema e a formulação de soluções. Na prática, constitui-se basicamente de 
um diagrama que mostra a relação entre uma característica da qualidade e os fatores, permitindo que seja identificada uma relação significativa entre um efeito e suas possíveis causas.

Barros e Bonafini (2014) apresentam o objetivo do diagrama de Ishikawa dizendo que o mesmo é usado para identificar a relação entre as causas e os efeitos de um processo, buscando-se as circunstâncias e analisando aquilo que se convencionou chamar de 6 M's.

Figura 1. Resultado da análise de entrevista - Diagrama de Ishikawa

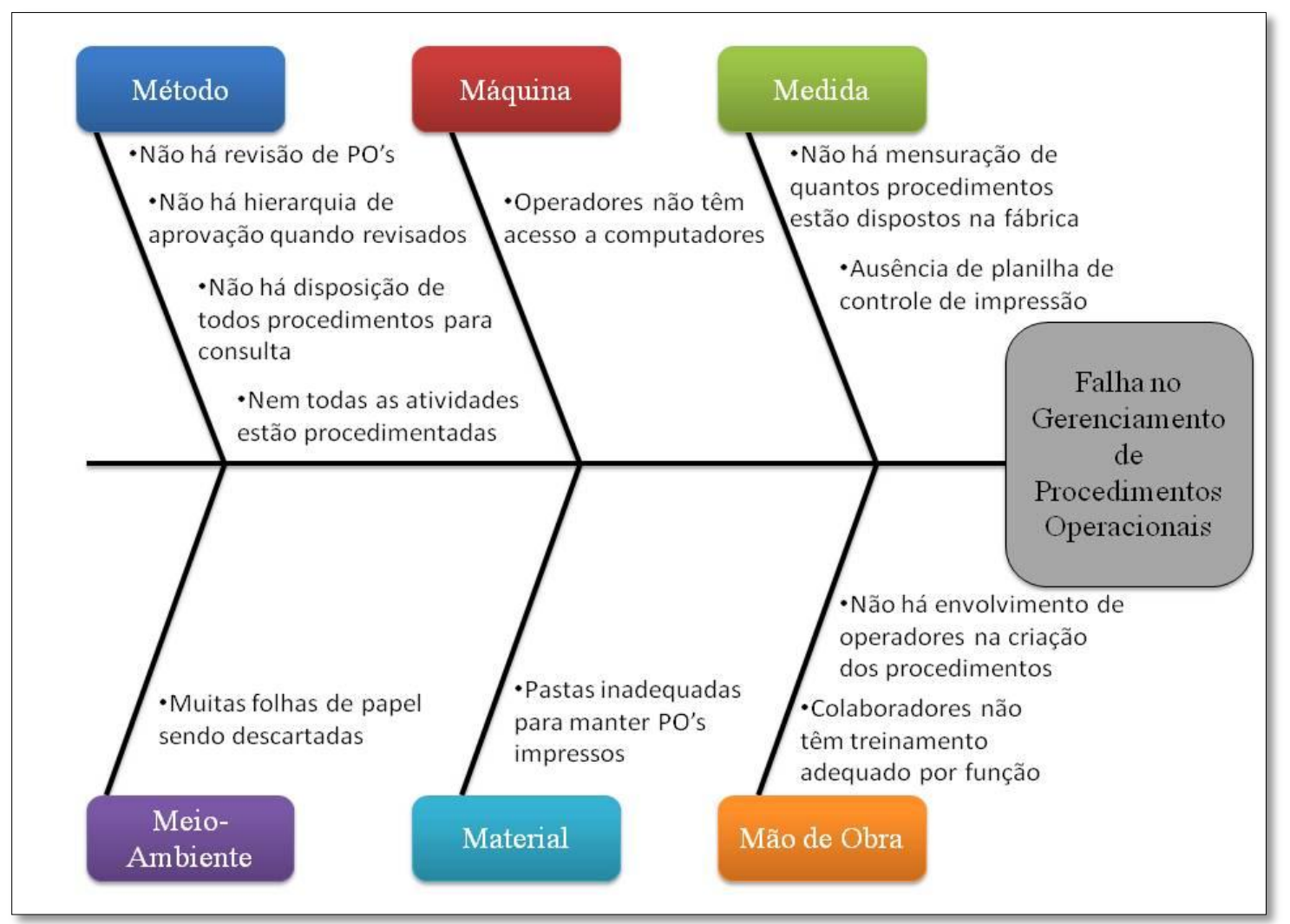

Fonte: Própria, 2015.

O Diagrama de Ishikawa permite expor as possíveis causas que geram o efeito ao qual este artigo tende a propor solução. Estas causas estão subdividas em seis fatores: Método, Máquina, Meio Ambiente, Mão de Obra, Medida e Material.

\subsection{Método}

Os fatores de métodos estão voltados para os meios pelos quais as atividades são executadas, este ponto, apresentada grande envolvimento com as funções básicas de toda tarefa. Seleme e Stadler (2012) apresentam Método como a forma como serão desenvolvidas as ações. 
Barros e Bonafini (2014) exemplificam este aspecto como procedimentos, normas, regras, leis, instruções de trabalho.

Através da reunião com o grupo de colaboradores, o fator Método apresentou maior número de causas ressaltantes, dentre elas, a ausência de revisão dos procedimentos operacionais, o que acarreta em incompatibilidade do documento com as atividades executadas, a ausência de hierarquia de aprovação para revisão gera uma descrição supérflua das atividades, pois os elaboradores nem sempre são os mesmos funcionários que executam as tarefas relacionadas. Outros aspectos negativos são: a ausência de disponibilidade de procedimentos para consulta durante a execução da tarefa e a falta de procedimentação de algumas atividades chaves.

\subsection{Máquina}

Os equipamentos são parte essencial da análise no diagrama de causa e efeito pois apresentam a interação do maquinário dentro do problema. É demonstrado através da obra de Barros e Bonafini (2014) alguns exemplos de causas oriundas do fator máquina, como: máquina quebrada, ausência de equipamentos, ausência de proteção, condições inseguras, falta de manutenção.

O aspecto analisado como Máquina é conceituado por Seleme e Stadler (2012) através da passagem: Diz respeito à operacionalização do equipamento e ao seu funcionamento adequado.

Como demonstrado anteriormente, o fator máquina apresenta apenas uma variável problemática que está ligada ao fato de alguns operadores não terem acesso a computadores, dificultando a disposição de procedimentos operacionais padrões para este grupo de utilizadores.

\subsection{Medida}

Os indicadores e objetos de medição estão agrupados no fator Medida, onde apresenta os dados de acompanhamento que poderiam interferir na problemática analisada. Seleme e Stadler (2012) apresentam este ponto dizendo que é traduzida pela forma como os valores são representados (por distância, tempo, temperatura etc.) e pelos instrumentos de medição utilizados. Para que o conceito seja mais claro, Barros e Bonafini (2014) apresentam algumas causas, como: ausência de verificação, processo de risco sem monitoramento, ausência de inspeção, ausência de indicador, dados não confiáveis.

Através do diagrama de causa e efeito aplicado na KB Cervejarias, podemos ver que os problemas enquanto a Medida, dizem respeito á falta de mensuração de resultado enquanto a quantidade de procedimentos operacionais dispostos no território da fábrica 
e ausência de planilha de controle de impressão. Ambas as problemáticas geram descontrole enquanto a disposição dos procedimentos dentro da empresa.

\subsection{Meio-Ambiente}

Os aspectos ambientes não estão apenas voltados para o impacto direcionado ao ambiente externo da organização, aqueles que afetam a comunidade, mas sim, enquadra, o ambiente interno e as premissas que possam causar um efeito negativo para os negócios. Comprovando tal afirmação Barros e Bonafini (2014) apresentam alguns exemplos: temperatura, umidade, sujeira, local desprotegido, desorganizado.

Seleme e Stadler (2012) dizem que o meio-ambiente avalia qual situação pode ser a causa de um determinado efeito (situações de execução e/ou infraestrutura fixa).

No estudo de caso apresentado foi evidenciado o grande número de folhas de papel descartadas por conta da grande demanda de impressão de procedimentos, já que, pela ausência de controle, a maioria destes documentos acaba se perdendo e quando necessários são impressos novamente.

\subsection{Material}

Os Materiais apresentam estruturas e meios aos quais o Método pode ser desenvolvido, sendo assim, os materiais disponíveis devem propor maior facilidade para desenvolver um ambiente de padronização. Seleme e Stadler (2012) demonstram que estes fatores são referentes a analise das características de materiais quanto à sua uniformidade, padrão e etc.

Na obra de Barros e Bonafini (2014) podemos encontrar problemas relacionados a materiais enquanto a quantidade insuficiente, qualidade ruim, ausência de fornecedor, e fora da especificação.

As pastas inadequadas para manter os procedimentos impressos na empresa em estudo foi uma das contribuições para o efeito negativo relacionado ao gerenciamento de procedimentos operacionais, gerando desgaste dos documentos criando condições negativas para consulta e treinamento por parte do quadro funcional.

\subsection{Mão de Obra}

Os aspectos relacionados à mão de obra condizem com todas as causas que podem ser geradas através das pessoas, sendo advindo de suas atividades ou da falta de suporte dado pela organização. Seleme e Stadler (2012) dizem que este fator caracteriza o padrão da mão de obra utilizada, se ela é devidamente treinada, se tem as habilidades necessárias, enfim, se está qualificada para o desempenho da tarefa. 
$\mathrm{Na}$ empresa analisada, encontramos problemas enquanto a ausência de documento formal garantindo a capacitação dos colaboradores nos procedimentos operacionais que estão inter-relacionados com suas atividades, além de não haver descrição de todos os procedimentos que as funções atuantes requisitam e a falta de envolvimento de todo o quadro de colaboradores na criação e revisão dos documentos de padronização das atividades, sendo assim, a empresa acaba excluindo do processo de padronização as pessoas que tem maior relação com as atividades e tarefas enquadradas.

\section{Conclusões}

Analisou-se neste artigo os aspectos contribuintes para a queda do indicador de retrabalho do objeto em estudo, KB Cervejarias. O principal aspecto ligado á essa perda de eficiência está voltado para o mal gerenciamento dos documentos operacionais padrões, ou, procedimentos operacionais. A ausência de confiabilidade nessa ferramenta gerou na organização um alto índice de problemáticas com padronização e desqualificação do quadro funcional. As atividades, conforme demonstrado, estavam sendo efetuadas desordenadamente levando a uma grande repetibilidade de execuções de tarefas para garantir que o produto final saísse com os aspectos desejados pelo cliente.

A KB Cervejarias vem enfrentando este problema por anos de atuação e não houve o estudo analítico com foco na melhoria do sistema de gerenciamento de procedimentos operacionais. Estes documentos encontravam-se defasados, em versões desatualizadas, com cópias descontroladas enquanto sua revisão, com ausência de conteúdo e impactava internamente nos colaboradores, que representaram o reflexo da alta administração da organização, a visão de que a sistemática de padronização já não era viável e muito pouco confiável.

Diante da problemática explicita ao gerente de planta, o grupo gerencial facilitou acesso ás informações e disponibilizou datas agendadas para ações que interrelacionavam padronização com a metodologia de pesquisa. Os colaboradores, por sua vez, no decorrer das pesquisas aplicadas, desenvolveram priorização ás atividades relacionadas ao resgate do gerenciamento e controle de procedimentos, visando que a melhoria a ser implementada nesse processo, seria de grande utilidade para garantir os aspectos íntegros do produto e a segurança dos colaboradores inteiramente associados com as tarefas.

Os aspectos negativos encontrados foram associados á metodologia de 6 M's, comumente conhecida como Diagrama de Ishikawa, afim de facilitar a explanação detalhada das causas que impactavam no desenvolvimento do controle de documentos.

Verificamos a necessidade de centralização do processo de controle e gerenciamento de procedimentos operacionais à área de Sistema de Gestão da Qualidade, ao qual deve criar rotinas que fiscalize a disposição destes documentos nas 
áreas sem acesso a computadores com o uso de pastas controladas, assim como nas áreas com acesso a sistema de informação tais documentos estariam disponíveis através de software de gerenciamento de padrões operacionais, Loyal. O sistema Loyal é uma central com banco de dados que garante a efetiva criação de usuários para acessar, revisar e criar procedimentos operacionais. Através de tal ferramenta do sistema de informação, a organização ganharia em efetividade dos dados disponíveis proporcionalmente para todos os funcionários que necessitam de tais informações.

Com a aplicação correta das metodologias propostas o desempenho da organização tende a alavancar no mundo onde o diferencial competitivo encontra-se em disseminar o conhecimento, a utilização de sistemas de informações auxiliam nestes resultados, com isso, a KB Cervejarias realizaria uma reestruturação no mercado, ganhando confiabilidade de seus colaboradores e fidelização dos clientes como resultado de produtos de qualidade.

\section{Referências}

BARROS, Elsimar; BONAFINI, Fernanda. Ferramentas da qualidade. São Paulo: Pearson Education do Brasil, 2014.

CAMPOS, Vicente Falconi. Qualidade Total: Padronização de empresas. 2. ed. Nova Lima: Editora FALCONI, 2014.

CARREIRA, Dorival. Organização, Sistemas e Métodos: ferramentas para racionalizar a rotina de trabalho e a estrutura organizacional da empresa. 2. ed. São Paulo: Saraiva, 2009.

CHIAVENATO, Idalberto. Introdução à teoria geral da administração. 4. ed. Baruerí, SP: Manole, 2014.

EXAME.COM. Quais as maiores empresas estrangeiras no Brasil? Out. 2013. Disponível em: <http://exame.abril.com.br/revistaexame/edicoes/104402/noticias/quais-as-maiores-empresas-estrangeiras-nobrasil\#curriculo62>. Acesso em: 15 jul. 2015.

LOBO, Renato Nogueirol; SILVA, Damião Limeira da. Gestão da Qualidade: Diretrizes, Ferramentas, Métodos e Normatização. 1. ed. São Paulo: Érica, 2014.

O'BRIEN, James A; MARAKAS, George M. Administração de sistemas de informação. 15. ed. Porto Alegre: AMGH, 2013.

PEARSON, Academia. Gestão da qualidade. 1. ed. São Paulo: Pearson Education Brasil, 2011. 
REIS, Linda G. Produção de Monografia: da teoria à pratica. 2. ed. Brasília: SenacDF, 2008.

REZENDE, Denis Alcides. Engenharia de Software e Sistemas de Informação. 3. ed. Rio de Janeiro: Brasport, 2005.

REZENDE, Denis Alcides. Sistemas de informações organizacionais: guia prático para projetos em cursos de administração, contabilidade e informática. 5. ed. São Paulo: Atlas, 2013.

RIBEIRO NETO, João Batista M; TAVARES, José da Cunha; HOFFMANN, Silvana Carvalho. Sistema de gestão integrados: qualidade, meio ambiente, responsabilidade social, segurança e saúde no trabalho. 4. ed. São Paulo: Editora Senac, 2013.

SELEME, Robson; STADLER, Humberto. Controle da qualidade: as ferramentas essenciais [livro eletrônico]. Curitiba: InterSaberes, 2012.

VERGARA, Sylvia Constant. Projetos e relatórios de pesquisa em Administração. 14. ed. São Paulo: Atlas, 2013.

VERRI, Lewton Burity. Comunicações Operacionais e da Qualidade: A fronteira final da garantia. 1. ed. Rio de Janeiro: Clube de Autores, 2009.

THIELMANN, Ricardo; SCHMIDT, Viviane Lisovski. O impacto da certificação do sistema de gestão da qualidade: um estudo multicasos em empresas da região sul fluminense. Rio de Janeiro, 2014. Disponível em: 〈http://www.congressocasi.uff.br/wpcontent/uploads/2014/07/Parte_2_CASI_2014.zip>. Acesso em: 23 Jul. 2015. 